\title{
Chemopreventive Effects of Korean Red Ginseng (Panax ginseng Meyer) on Exposure to Polycyclic Aromatic Hydrocarbons
}

\author{
Ho-Sun Lee ${ }^{1}$, Jong Yun Park², and Mihi Yang ${ }^{1^{*}}$ \\ ${ }^{1}$ College of Pharmacy, Sookmyung Women's University, Seoul 140-742, Korea \\ ${ }^{2}$ Division of Cancer Prevention and Controls, H. Lee Moffitt Cancer Center and Research Institute, Tampa, FL 33612, USA
}

Polycyclic aromatic hydrocarbons (PAHs) are well known environmental carcinogens. PAH metabolites, especially BaP-7,8dihydrodiol, 9,10 epoxide, initiate carcinogenesis via high specificity binding to DNA to form DNA adducts. The Korean red ginseng (KRG) from Panax ginseng has been suggested to protect against damages due to PAH exposure but the mechanism is unknown. Therefore, we investigated effects of KRG on PAH exposure using toxicokinetic methods and changes of PAH-induced oxidative damage during a 2 week-clinical trial ( $n=21$ healthy young female, $23.71 \pm 2.43$ years). To analyze antioxidative effects of KRG, we measured changes in the levels of urinary malondialdehyde (MDA) before and after KRG treatment. We observed a significant positive association between levels of urinary MDA and 1-hydroxypyrene, a biomarker of PAH exposures (slope=1.47, $p=0.03$ ) and confirmed oxidative stress induced by PAH exposures. A reverse significant correlation between KRG treatment and level of urinary MDA was observed $(p=0.03$ ). In summary, results of our clinical trial study suggest that KRG plays a significant role in antioxidative as well as toxicokinetic pathways against PAHs exposure.

Keywords: Korean red ginseng, Aromatic polycyclic hydrocarbons, 1-Hydroxypyrene, Malondialdehyde, Chemoprevention

\section{INTRODUCTION}

Polycyclic aromatic hydrocarbons (PAHs) including benzo $(\alpha)$ pyrene $(\mathrm{BaP})$ are well-known environmental pollutants [1]. As PAHs are generated by incomplete combustion of carbon $(\mathrm{C})$ and hydrogen $(\mathrm{H})$ compounds, the general population are exposed to PAHs everyday, e.g. through grilled food or air pollution including tobacco smoke [2]. PAHs can undergo metabolic activation to potent ultimate carcinogens by mean of cytochrome P450 monooxygenase enzymes that catalyze the bioactivation of many procarcinogens. A key metabolic enzyme is cytochrome P4501A1 which initiates the formation of reactive oxygen species (ROS) and catalyzes the conversion of $\mathrm{BaP}$ into potent carcinogens and mutagenic agents. These processes contribute to carcinogenesis via DNA

(c) This is an Open Access article distributed under the terms of the Creative Commons Attribution Non-Commercial License (http://creativecommons.org/licenses/by-nc/3.0/) which permits unrestricted non-commercial use, distribution, and reproduction in any medium, provided the original work is properly cited. damage [3]. Therefore, for several decades many countries have tried to reduce the volume of PAHs production by governmental regulations. Most PAH regulation agencies monitor PAH exposures particularly 1-hydroxypyrene (1-OHP), a major metabolite of pyrene, which is used as a representative biomarker for PAH exposure [4]. Recently, detoxification of carcinogens as well as regulation of exposure to environmental carcinogens has been emphasized to protect the health of individuals. Ideal chemopreventive agents for consumed PAHs in human body should accelerate excretion of PAHs by metabolism or indirect scavenging, e.g. antioxidative effects against PAHs-induced ROS. Among these agents, we focused on Korean red ginseng (KRG, P. ginseng) that has been

Received 28 Dec. 2010, Revised 20 Apr. 2011, Accepted 20 Apr. 2011

*Corresponding author

E-mail: myang@sm.ac.kr

Tel: +82-2-2077-7179, Fax: +82-2-710-9781 
processed for enhancing efficacy, safety, and preservation of raw ginseng. KRG is a well known traditional medicine with multiple biological functions including anti-oxidation, detoxification [5] and chemoprevention against PAHs. Therefore, in order to assess a chemoprevention potential of KRG against carcinogenic PAHs, we performed pharmaco- or toxico-kinetic analyses with monitoring of urinary 1-OHP and analyzed changes in malondialdehyde (MDA), a biomarker for oxidative damage [6].

\section{MATERIALS AND METHODS}

\section{Materials}

HPLC grade acetonitrile and methanol were obtained from Thermo Fischer Scientific (Waltham, MA, USA). Thiobarbituric acid (TBA), 1, 1, 3, 3-tetrethoxypropane (TEP), 1-OHP and $\beta$-glucuronidase (type H-2, Helixpomatia) were purchased from the Sigma-Aldrich (St. Louis, MO, USA). KRG capsules were kindly provided from the Korea Ginseng Corporation (Seoul, Korea). These KRG capsules contained $300 \mathrm{mg}$ of freeze-dried powder of 6-years old KRG.

\section{Study subjects}

This trial was designed as a single-blind randomized study, which was approved by Institutional Review Boar) of the Sookmyung Women's University (\#SMIRB-09-0506). All participants filled out the informed consent form before participating in this study.

Volunteers were recruited by bulletins in Sookmyung Women's University, Seoul and responded to an initial questionnaire to screen for their eligibility. Individuals on prescription drugs and/or having their menstrual periods were excluded. Twenty one young, healthy and nonsmoker-females (age, 23.71 \pm 2.43 years; weight, $52.81 \pm 4.59 \mathrm{~kg}$ ), who were at the same phase of menstrual cycle, participated in this study. Subjects were advised to take 9 capsules of KRG (2.7 g of KRG powder)/d for 2 wk. During the trial period, all subjects were requested daily to complete a questionnaire on lifestyle and food consumption. Urine specimens were collected before breakfast on day $1,4,7$, and 14 and stored at $-20^{\circ} \mathrm{C}$ until analysis was performed.

\section{Analysis of urinary 1-hydroxypyrene}

Levels of urinary 1-OHP were measured as published previously by our group [4]. Briefly, $200 \mathrm{uL}$ of each urine sample was buffered with $200 \mathrm{uL}$ of $0.2 \mathrm{M}$ sodium acetate ( $\mathrm{pH}$ 5.0) and hydrolyzed with $\beta$-glucuronidase for $5 \mathrm{~h}$ at $37^{\circ} \mathrm{C}$ in shaking water bath. After enzyme-hydrolysis, $500 \mathrm{uL}$ of acetonitrile was added to the mixture and centrifuged at $14,000 \times \mathrm{g}$ for $10 \mathrm{~min}$. HPLC system was consisted of dual Yonglin SP930D pumps (Younglin, Seoul, Korea), a MIDAS COOL autosampler (Spark Holland, Emmen, The Netherlands), a Jasco FP-2020 plus fluorescence detector (Jasco, Great Dummow, UK) and a X-terra C18 column $(46 \times 250 \mathrm{~mm}$; Waters, Milford, MA, USA). We used mobile phase of $58 \%(\mathrm{v} / \mathrm{v})$ acetonitrile in water. Excitation and emission wavelengths for 1-OHP detection were 242 and $388 \mathrm{~nm}$, respectively. For establishing a calibration curve, we obtained appropriate coefficient of variations $(<10 \%)$. The detection limit for 1-OHP was $0.077 \mathrm{ug} / \mathrm{L}$ from triplicate measurements at 5 different concentrations $(0.1-20 \mathrm{ug} / \mathrm{L})$. Urinary 1-OHP level of each sample was adjusted for urinary creatinine values [7].

\section{Analysis of urinary malondialdehyde}

We analyzed urinary MDA concentration with the above HPLC system using the method published by Tagesson et al. [6] with modifications: detector, Shimadzu SPD-10A UV/VIS Detector (Shimadzu corporation, Tokyo, Japan); column, a Sunfire ${ }^{\mathrm{TM}} \mathrm{C} 18,3.5$ um $(150 \times 4.6$ $\mathrm{mm}$; Waters, Milford, MA, USA); mobile phase, $50 \mathrm{mM}$ of potassium phosphate buffer ( $\mathrm{pH} 6.8) /$ methanol (58:42, $\mathrm{v} / \mathrm{v} \%$ ); flow rate, $0.8 \mathrm{~mL} / \mathrm{min}$; UV, $532 \mathrm{~nm}$.

Briefly, $300 \mathrm{uL}$ of phosphoric acid $(0.5 \mathrm{~mol} / \mathrm{L})$ was added to $50 \mathrm{uL}$ of each urine sample and mixed with 150 $\mathrm{uL}$ of $23 \mathrm{mM}$ TBA in $1.5 \mathrm{~mL}$ plastic centrifuge tubes with screw-on caps. Samples were mixed, heated on a $95^{\circ} \mathrm{C}$ dry bath incubator for $1 \mathrm{~h}$, and cooled on ice. After cooling, $500 \mathrm{uL}$ of methanol was added to the mixture. Then $200 \mathrm{uL}$ of the supernatant from the resulting mixture was injected to HPLC.

For MDA calibration, different concentrations of TEP were prepared daily as standards. Detection limit of MDA was $0.63 \mathrm{umol} / \mathrm{L}$. The calibration curve was obtained from triplicate analyses of 5 different standard TEP concentrations $(0.1-20 \mathrm{umol} / \mathrm{L})$. Their coefficient variations were less than $10 \%$. Urinary MDA levels were also corrected by urinary creatinine values [7].

\section{Statistical analyses}

The degree of normal distribution of 1-OHP and MDA levels were analyzed with Shapro-Wilk W test. Because levels of 1-OHP and MDA did not follow the normal distribution $(p<0.01)$ (Fig. 1), Wilcoxon test was used for analysis of 1-OHP or MDA levels. Effects of KRG (time course) on levels of urinary 1-OHP and MDA 


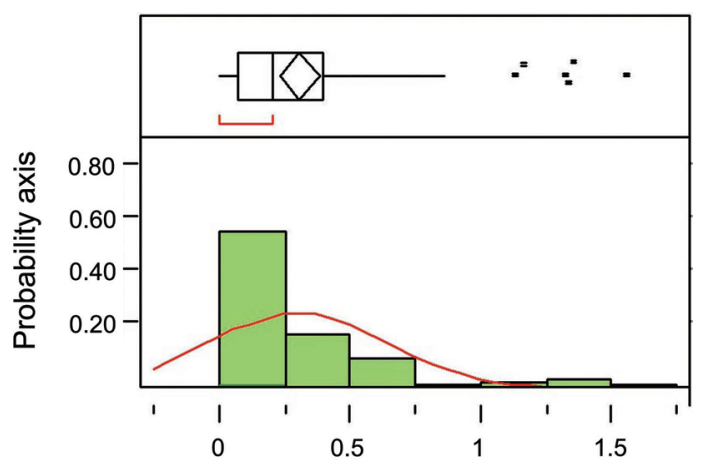

Fig. 1. Histogram of urinary 1-hydroxypyrene (ug/L) with outliers: upper part of figure shows an outlier box plot with interquartile range $(n=84)$.

were analyzed with regression analyses. All statistical analyses were performed with JMP ver. 4 (SAS Institute, Cary, NC, USA). Statistical significance was defined as $p<0.05$.

\section{RESULTS}

\section{Characteristics of subjects}

Body mass indexes of all subjects, $19.5 \pm 1.07 \mathrm{~kg} / \mathrm{m}^{2}$, were in the normal range based on the World Health Organization classification [8]. During the trial period, study participants were advised to keep under control the consumption of grilled meats or greasy food in order to avoid compounding factor, which may affect urinary 1-OHP levels. While most of subjects followed the recommendations during most of trial period, some participants consumed food containing high levels of PAH at several points. Therefore, their values of 1-OHP and MDA were excluded from statistical analyses.

\section{Association between urinary 1-OHP and MDA levels}

Levels of urinary 1-OHP and MDA ranged from non detectible to $1.56 \mathrm{ug} / \mathrm{L}$ (median, $0.20 \mathrm{ug} / \mathrm{L}$ ) and 0.37 to $17.04 \mathrm{uM}$ (median, $2.43 \mathrm{uM}$ ), respectively. Levels of urinary 1-OHP and MDA were detected in all subjects except one. A significant correlation was observed between levels of urinary 1-OHP and MDA (Fig. 2). These results imply that PAHs induced oxidative damages and these damages may play a role in PAH-related carcinogenesis.

\section{Effects of KRG on urinary 1-OHP and MDA}

Both urinary 1-OHP and MDA levels were decreased during the period of KRG treatment (Fig. 3). However, these trends were not statistical significant after creatinine correction (slope $=-0.01, p=0.58$, slope $=-0.04, p=0.17$ ). We observed a statistically significant decrease between

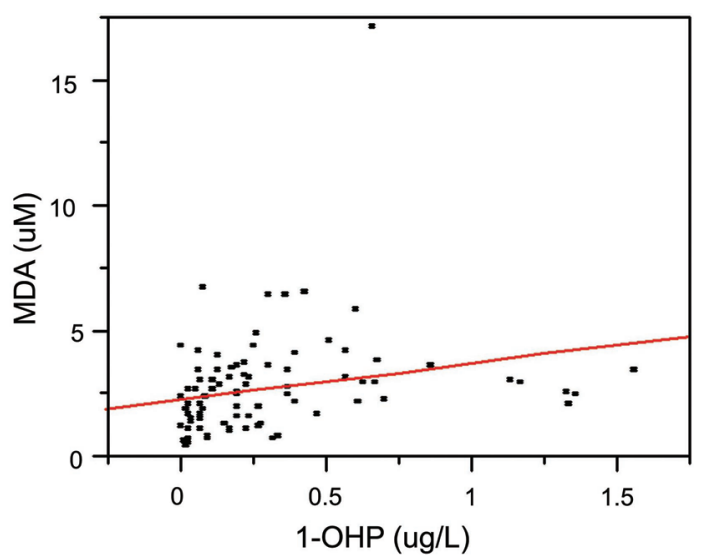

Fig. 2. Positive association between urinary 1-hydroxypyrene (1$\mathrm{OHP}$ ) and malondialdehyde (MDA) levels ( $n=84$; slope $=1.47, p=0.03$ by regression analysis)

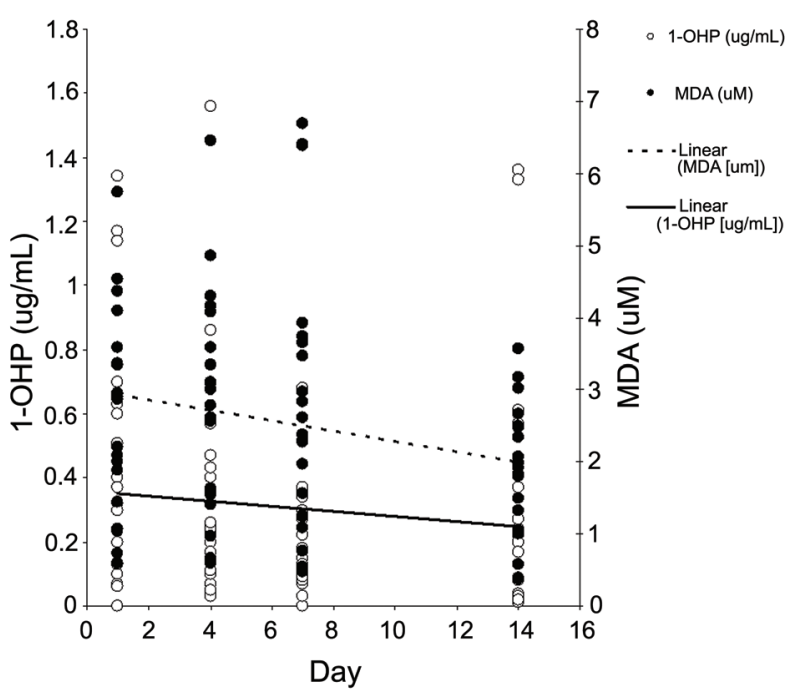

Fig. 3. Korean red ginseng treatments decreased levels of urinary 1-hydroxypyrene (1-OHP) and malondialdehyde (MDA): slope $=-0.01$ $(p=0.20)$ and $-0.07(p=0.03)$, respectively by regression analyses.

levels of MDA on day 1 and day14 $(p=0.02)$. However, after creatinine modification of MDA levels ( $\mathrm{uM} / \mathrm{g}$ creatinine), this difference was no longer significant ( $p=0.47$ by Wilcoxon test).

\section{DISCUSSION}

Levels of 1-OHP (median, $0.2 \mathrm{ug} / \mathrm{L}$ ) in the present study were within the range reported from previous studies including ours [4,9]. Based upon the characteristics of subjects, nonsmokers and young females, we assumed that food was a major exposure route of PAHs. Therefore, the 1-OHP levels in this study may reflect exposure from food-born PAHs rather than air-born PAHs. This 
assumption was further supported by a similar range of urinary MDA levels between the present study (median, $2.43 \mathrm{uM}$, approximately $0.17 \mathrm{mg} / \mathrm{g}$ creatinine) and a previous study among Korean women study $(0.18 \pm 1.10$ to $0.37 \pm 1.11 \mathrm{mg} / \mathrm{g}$ creatinine) [10].

PAHs can induce oxidative stress indirectly, through biotransformation by cytochrome P450s, epoxide hydrolase, and dihydrodiol dehydrogenase to generate redox active quinones $[3,11]$. Free radicals of the reactive quinones can react further with lipids causing peroxidation, resulting in the release of products such as MDA, hydroperoxides and hydroxyl radical. These oxidative stresses may participate in all stages of the carcinogenesis process, namely initiation, promotion, and progression. Several studies have examined the relationship between occupational exposure to PAHs and oxidative stress biomarkers. Hu et al. [12] reported a strong correlation between urinary levels of 8-hydroxy-2'-deoxyguanosine (8-OHdG), a marker of oxidative stress to DNA, and 1-OHP among coke oven workers. In the present study, we found a positive correlation between urinary 1-OHP and MDA levels (Fig. 2). The finding of our present study is supported by a recent Chinese study that also reported a positive correlation between the two biomarkers [13]. Therefore, the levels of urinary MDA, which represents oxidative stress in body, may reflect a degree of PAHs exposure. As expected, results of our study suggested bioproduction of ROS and oxidative damage by PAHs exposure as a mechanism of PAHs-related carcinogenesis. Therefore, antioxidative effects of KRG may play a critical role in the prevention of $\mathrm{PAH}$-induced carcinogenesis.

Previous studies reported that KRG intake reduced levels of 8-OHdG $[14,15]$. In addition, KRG showed antioxidant effects on superoxide dismutase in non-insulindependent diabetic mellitus (NIDDM) patients and on reduction of MDA in NIDDM rats [16,17]. In the present study, we found that KRG intake significantly reduced urinary MDA levels (Fig. 3).

In conclusion, the data generated from this study suggest chemopreventive effects of KRG on PAH-related damages via direct antioxidative activity as well as toxicokinetic mechanisms.

\section{ACKNOWLEDGEMENTS}

This work was supported by the 2009 grant from the Korean Society of Ginseng funded by Korea Geinseng Corporation. We appreciate Dr. Ernest Amankwah's excellent editing for our manuscript.

\section{REFERENCES}

1. IARC Working Group on the Evaluation of Carcinogenic Risks to Humans. Some non-heterocyclic polycyclic aromatic hydrocarbons and some related exposures. Lyon: IARC Press, 2010.

2. Yang M, Kim S, Lee E, Cheong HK, Chang SS, Kang D, Choi Y, Lee SM, Jang JY. Sources of polycyclic aromatic hydrocarbon exposure in non-occupationally exposed Koreans. Environ Mol Mutagen 2003;42:250-257.

3. Sabo-Attwood T, Ramos-Nino M, Mossman BT. Environmental carcinogens. In: Chang AE, Ganz PA, Hayes DF, Kinsella TJ, Pass HI, eds. Oncology: an evidence-based approach. New York: Springer, 2006. p.233-243.

4. Yang M, Jang JY, Kim S, Lee SM, Chang SS, Cheong HK, Lee E, Kang D, Kim H, Kawamoto T et al. Genetic effects on urinary 1-hydroxypyrene levels in a Korean population. Carcinogenesis 2003;24:1085-1089.

5. Shukla R, Kumar M. Role of Panax ginseng as an antioxidant after cadmium-induced hepatic injuries. Food Chem Toxicol 2009;47:769-773.

6. Tagesson C, Kallberg M, Wingren G. Urinary malondialdehyde and 8-hydroxydeoxyguanosine as potential markers of oxidative stress in industrial art glass workers. Int Arch Occup Environ Health 1996;69:5-13.

7. Ogata M, Taguchi T. Simultaneous determination of urinary creatinine and metabolites of toluene, xylene, styrene, ethylbenzene and phenol by automated high performance liquid chromatography. Int Arch Occup Environ Health 1988;61:131-140.

8. World Health Organization. Global database on body mass index. Available from: http://apps.who.int/bmi.

9. Hong YC, Park EY, Park MS, Ko JA, Oh SY, Kim H, Lee KH, Leem JH, Ha EH. Community level exposure to chemicals and oxidative stress in adult population. Toxicol Lett 2009;184:139-144.

10. Lee KH, Bartsch H, Nair J, Yoo DH, Hong YC, Cho SH, Kang D. Effect of short-term fasting on urinary excretion of primary lipid peroxidation products and on markers of oxidative DNA damage in healthy women. Carcinogenesis 2006;27:1398-1403.

11. Penning TM, Burczynski ME, Hung CF, McCoull KD, Palackal NT, Tsuruda LS. Dihydrodiol dehydrogenases and polycyclic aromatic hydrocarbon activation: generation of reactive and redox active o-quinones. Chem Res Toxicol 1999;12:1-18.

12. Hu CW, Wu MT, Chao MR, Pan CH, Wang CJ, Swenberg JA, Wu KY. Comparison of analyses of urinary 8-hydroxy-2'-deoxyguanosine by isotope-dilution liquid chromatography with electrospray tandem mass spectrometry 
and by enzyme-linked immunosorbent assay. Rapid Commun Mass Spectrom 2004; 18:505-510.

13. Pan CH, Chan CC, Huang YL, Wu KY. Urinary 1-hydroxypyrene and malondialdehyde in male workers in Chinese restaurants. Occup Environ Med 2008;65:732735.

14. Kim HS, Lee BM. Protective effects of antioxidant supplementation on plasma lipid peroxidation in smokers. J Toxicol Environ Health A 2001;63:583-598.

15. Lee BM, Lee SK, Kim HS. Inhibition of oxidative DNA damage, 8-OHdG, and carbonyl contents in smokers treated with antioxidants (vitamin E, vitamin C, beta-carotene and red ginseng). Cancer Lett 1998;132:219-227.

16. Choi KM, Lee EJ, Kim YH, Baik SH, Kim YK, Choi DS. Effects of red ginseng on the lipid peroxidation of erythrocyte and antioxidant superoxide dismutase (SOD) activity in NIDDM patients. Korean J Ginseng Sci 1997;21:153-159.

17. Ryu JK, Lee T, Kim DJ, Park IS, Yoon SM, Lee HS, Song SU, Suh JK. Free radical-scavenging activity of Korean red ginseng for erectile dysfunction in non-insulin-dependent diabetes mellitus rats. Urology 2005;65:611-615. 